\title{
Labor, trabalho e ação: elementos pertinentes aos conceitos arendtianos em relatos autobiográficos de trabalhadores do setor de transportes
}

\section{Labor, work, and action: relevant elements regarding Arendt's concepts in autobiographical reports of workers from the transportation sector}

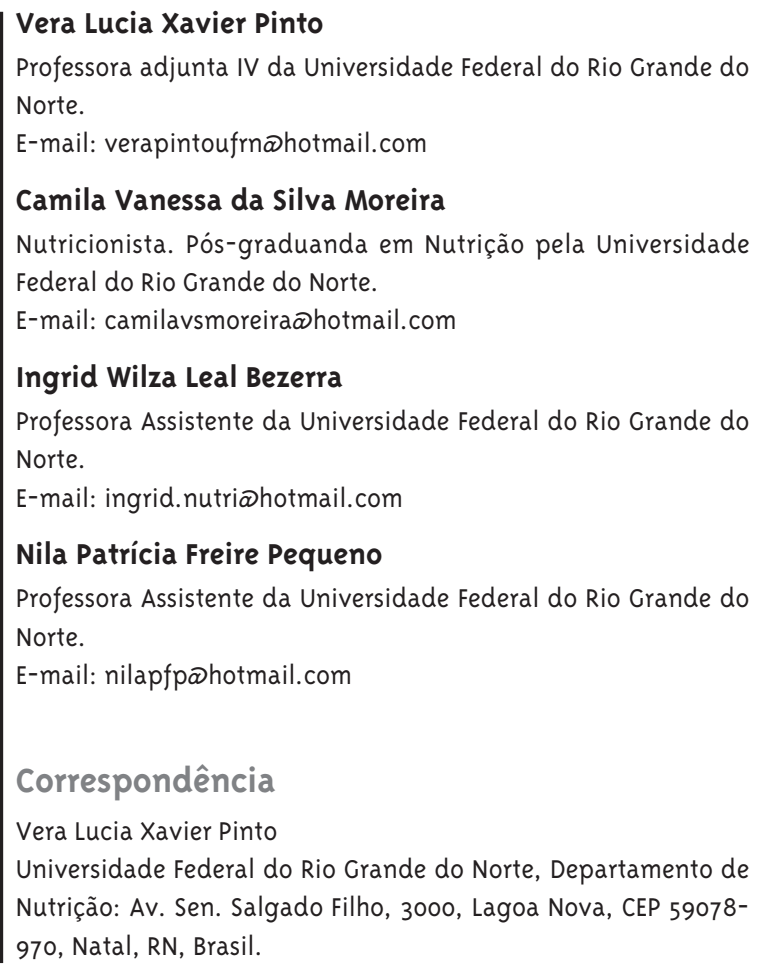

\section{Correspondência}

Vera Lucia Xavier Pinto

Universidade Federal do Rio Grande do Norte, Departamento de Nutrição: Av. Sen. Salgado Filho, 3000, Lagoa Nova, CEP 59078970, Natal, RN, Brasil.

\section{Resumo}

A reflexão, junto à classe trabalhadora, sobre questões relacionadas à saúde no ambiente de trabalho, visando à criticidade e às ações que resultem no enfrentamento de seus problemas é um importante instrumento de mudança da realidade. 0 objetivo desta pesquisa exploratória é identificar elementos pertinentes aos conceitos arendtianos (labor, trabalho e ação) presentes no discurso de trabalhadores do setor de transportes participantes de um projeto de extensão universitária. A abordagem é qualitativa e a metodologia consiste em relato autobiográfico. As histórias dos trabalhadores foram gravadas em DVD e posteriormente transcritas. Para a análise, optou-se pela definição de categorias a priori (labor, trabalho e ação), uma vez que o marco teórico era a obra de Hannah Arendt. Como resultado, foram encontrados: insegurança alimentar, doenças crônicas não transmissíveis relacionadas ao conceito de labor; riscos ergonômicos e distúrbios psíquicos relacionados ao trabalho; e participação coletiva e inclusão digital como elementos da ação. Concluiu-se que conhecer, compreender e discutir essas três categorias para o incremento da reflexão acerca da saúde do trabalhador pode ser importante, uma vez que todas elas foram expressas nos relatos de vida, mostrando sua permanência e relevância na história de todos e de cada um.

Palavras-chave: Hannah Arendt; Saúde do Trabalhador; Setor de Transportes; Labor; Trabalho e Ação. 


\section{Abstract}

Reflection, along with the working class, on health-related issues at the workplace, aiming at criticality and actions that result in facing its problems, is a significant instrument to change reality. The purpose of this exploratory research is identifying relevant elements with regard to Arendt's concepts (labor, work, and action) observed in the discourse of workers from the transportation sector participating in a university outreach project. The approach is qualitative and the methodology is autobiographical account. Workers' histories were recorded on DVD and then transcribed. For the analysis, we chose to define a priori categories (labor, work, and action), since the theoretical framework was Hannah Arendt's work. As a result, we found: food insecurity, chronic noncommunicable diseases related to the concept of labor; ergonomic hazards and psychic disorders related to work; and collective participation and digital inclusion as elements of action. It was concluded that knowing, understanding, and discussing these three categories in order to increase the reflection on occupational health may be important, since all of them were expressed in life accounts, showing their permanence and relevance in the history of everybody and each one.

Keywords: Hannah Arendt; Occupational Health; Transportation Sector; Labor; Work and Action.

\section{Introdução}

Em sua obra intitulada “A condição humana” Arendt (1995) caracteriza a condição humana como algo mais complexo do que as condições nas quais a vida foi dada ao homem na terra. Segundo ela, os homens são seres condicionados, uma vez que tudo aquilo com que entram em contato torna-se imediatamente uma condição de sua existência. A condição humana representa características essenciais da existência do homem em determinado espaço, visto que sem elas essa existência deixaria de ser humana. Dessa forma, pode-se dizer que a vida, a natalidade e a mortalidade, a pluralidade e o planeta Terra pertencem à condição humana (Barreto, 2002).

A condição humana, segundo a autora, está relacionada a três atividades fundamentais que caracterizam a vida na terra: "labor", "trabalho" e "ação". Cada uma dessas atividades está diretamente relacionada às condições básicas nas quais a vida foi dada ao homem. O labor é a atividade correspondente ao processo biológico do corpo humano, tem a ver com as necessidades vitais produzidas e introduzidas no processo da vida. O labor assegura a sobrevivência do indivíduo e a vida da espécie (Arendt, 1995). 0 trabalho, ainda que não individualize o homem, permite a criação de objetos e a transformação da natureza, proporcionando a criação de um habitat distinto ao dos outros animais. Dirigido pela utilidade, permite ao homem demonstrar a sua habilidade e inventividade artesanal (Arendt, 1995). A ação, por sua vez, é a única atividade que independe da medição da matéria e se correlaciona com a condição humana da pluralidade. É por meio da ação que os homens são capazes de demonstrar quem são (Arendt, 1995).

Conhecer esses três aspectos da condição humana pode ser um elemento importante para a discussão das questões que perpassam a saúde e o

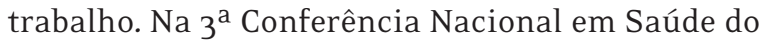
Trabalhador, realizada em 2005, foi evidenciada a necessidade de maior conhecimento sobre as condições de vida e trabalho do trabalhador brasileiro e de preparar os futuros profissionais, sejam da saúde ou de outras áreas, para a discussão e formulação de políticas públicas que minimizem os agravos sofridos por eles. Nesse contexto os movimentos 
de defesa da saúde do trabalhador foram criados com intuito de fomentar a reflexão sobre o tema e sensibilizar os gestores para um olhar mais acurado para os problemas existentes.

0 presente relato de experiência é fruto de reflexões realizadas em um projeto de extensão universitária intitulado "Vidas Paralelas" (PVP). Trata-se de uma iniciativa da Rede Escola Continental em Saúde do Trabalhador, desenvolvida em vários Estados brasileiros, com coordenação nacional da Universidade de Brasília e apoio dos ministérios da Cultura (MinC) e da Saúde (MS). O objetivo é contribuir para o desenvolvimento da criticidade da classe trabalhadora no que diz respeito a questões de saúde no ambiente de trabalho, usando a reflexão e a manifestação criativa acerca de sua realidade como ferramentas. Busca, ainda, contatar o conhecimento acadêmico e a prática social da classe trabalhadora, contribuindo para a transformação da sociedade e para a formação crítica dos estudantes.

O presente trabalho tem por objetivo relatar como foram articulados os elementos pertinentes aos conceitos arendtianos (labor, trabalho e ação) e o discurso de trabalhadores do setor de transportes participantes do projeto. O estudo exploratório foi adotado como guia ao relato de experiência, por constituir-se como o mais adequado. Buscou-se, primeiramente, familiarizar-se com o cotidiano dos trabalhadores, de forma a permitir uma melhor compreensão dos fatos e fatores que interferem ou se articulam na sua formação e compreensão de vida, articulando esses aspectos com um aporte teórico (as categorias propostas por Arendt) como parte de um processo que busca tanto desvelar condições de trabalho quanto obter respostas para o enfrentamento das problemáticas existentes.

\section{Metodologia}

O relato de experiência aqui apresentado é fruto da exploração do material produzido nos encontros e utiliza uma abordagem qualitativa de análise. 0 marco teórico referencial é a obra de Arendt (1995) intitulada "A condição humana", da qual foram utilizados os conceitos-chave ali expressos como categorias a priori. Labor, trabalho e ação são atividades relevantes porque a cada uma delas corresponde uma das condições primordiais nas quais a vida foi dada ao homem na Terra. O "labor", para Arendt, é a atividade que corresponde ao processo biológico do corpo humano; o "trabalho" corresponde ao artificialismo da existência humana; a "ação", por sua vez, corresponde à condição humana da pluralidade, ao fato de que homens - coletivo e não indivíduos vivem na Terra e habitam o mundo.

O PVP é um projeto de extensão para o qual foram convocados à participação categorias profissionais que apresentam um percentual expressivo de adoecimento por causas laborais. Foram articulados 24 trabalhadores em cada Estado da nação (12 do setor formal e 12 do informal), recebendo cada um deles um equipamento (aparelho celular ou câmera fotográfica) para registrar seu cotidiano. A produção de cada trabalhador ainda é apresentada nas reuniões mensais, realizadas junto à Rede de Apoio (formada por professores e estudantes universitários, bem como por profissionais e ativistas de outras instituições, em especial os sindicatos) com a finalidade de discuti-las. Nesses encontros, os participantes são apoiados na inserção da imagem ou vídeo em um blog criado pelo MinC para este fim, o que se configura também como um processo de inclusão digital.

A coordenação local do projeto de extensão é responsabilidade de um professor de uma universidade pública do Estado participante. Na Universidade Federal do Rio Grande do Norte (UFRN) as atividades do projeto são realizadas mensalmente, por meio de encontros que visam inserir os alunos da graduação de diferentes cursos no espaço da Rede de Apoio do projeto para conhecer, por meio da vivência com trabalhadores, o universo do trabalho, saúde e cultura; acompanhar os trabalhadores participantes do projeto na inclusão de suas produções digitais; refletir sobre os processos saúde-doença; e contribuir para o fortalecimento das redes sociais em construção. Um dos objetivos dos encontros é compreender os processos de vida-saúde-(auto)formação vivenciados pelos trabalhadores formais e informais no seu dia a dia, bem como proporcionar a compreensão dessas dimensões ao participar das discussões desencadeadas nos encontros e da contação de suas histórias de vida.

Dentre as categorias profissionais que participam deste projeto estão as do setor de transportes. 
Os trabalhadores desse setor estão frequentemente sujeitos a longas jornadas, horários irregulares e trabalho noturno. A necessidade de permanecer no trânsito por muitas horas compromete o sono, o estado de saúde e aumenta o risco de acidentes. Estão ainda expostos a condições adversas, criadoras de estresse, como as ambientais - condições das estradas e o tráfego de veículos, por exemplo - e as de natureza organizacional, como o tipo de turno e vínculo de trabalho (Ulhôa e col., 2010).

A história de vida foi a metodologia utilizada - num dado momento do projeto de extensão que desencadeou esta pesquisa - como um elemento formador, por ser um método capaz de promover o que Morin e Nair (1997) chama de "reforma do pensamento", por valorizar a compreensão que se desenvolve no interior da pessoa a partir das vivências experimentadas ao longo da vida.

Neste artigo evidencia-se a dupla função (instrumento de investigação e pedagógico) da abordagem biográfica. "A situação experimental necessária à investigação coincide com a acção educativa [...]” (Dominicé, 1988, p. 103).

A coleta dos materiais foi realizada nos encontros mensais do projeto de extensão citado. Neles os trabalhadores narraram livremente suas histórias de vida, sem interrupções, de modo a permitir a cada indivíduo focar nos acontecimentos considerados por eles mais relevantes. Findas as narrativas, os presentes faziam indagações sobre aspectos não comentados, ou sobre os quais tinham dúvidas, enquanto aos narradores era facultado o direito de responder também livremente. As histórias foram gravadas em câmera de vídeo, transferidas para mídia externa (DVD), posteriormente transcritas. Esses documentos formaram o corpus sobre o qual a análise foi realizada. Essa se deu pela definição de categorias a priori (labor, trabalho e ação) retiradas do marco teórico.

Os sujeitos cujos relatos ilustram essa pesquisa são dois trabalhadores do setor de transporte participantes da ação de extensão: um exerce a atividade de motorista e o outro de cobrador. 0 primeiro tinha 35 anos de idade à época da pesquisa e morava na capital, Natal. O segundo tinha 31 anos e vivia em outro município do mesmo Estado. Ambos trabalhavam no setor há mais de dez anos e referiam adoecimento por causas laborais. Aqui recebem os codinomes de Marcos e Luzimar, respectivamente, para que sejam preservadas suas identidades.

\section{Resultados e discussão}

\section{"O labor": a alimentação como elemento clave}

Olabor é a atividaderelacionada ao processo biológico do corpo humano: crescimento, metabolismo e seu declínio. Corresponde a uma condição nata de como determinados conhecimentos, um saber implícito, nascem com o homem. A condição humana do labor é a vida. Sua qualidade é de um estoque inicial de informação, que se acumula com o viver da vida. (Barreto, 2002, p. 67).

De acordo com Arendt, o labor é regido pelas exigências corpóreas. Algumas ações exercidas com a finalidade de atender às necessidades da vida por vezes são compreendidas como tal, no entanto, na maioria delas, os quesitos a serem satisfeitos não são fundamentalmente fisiológicos. Essa é a principal distinção estabelecida pela autora entre dois conceitos que, por vezes, são tomados como sinônimos: trabalho e labor. Este, para ela, trata essencialmente da satisfação de demandas vitais que são idênticas para o homem e os outros animais, enquanto aquele não.

Para a autora de "A condição humana" o labor é um processo cíclico, movido por um círculo prescrito - o processo biológico do organismo vivo -, e só finda com a morte. Esse ciclo é sustentado pelo consumo, e a atividade que provê os meios de consumo é o labor, preparando a matéria para incorporá-la ao trabalho. É fácil perceber, por essa definição, que o ato interminável e necessário de alimentar-se é um elemento importante do labor, e está intimamente relacionado à capacidade de realizar trabalho.

Para os sujeitos pesquisados, a vivência desse aspecto da condição humana, além de relacionarse à realização de atividades árduas, possui uma profunda relação com as condições adversas de vida e trabalho vivenciadas pelos brasileiros, e que se estende, inclusive, a seus familiares.

Ao relembrar sua infância, Luzimar relata o sacrifício realizado por ele, ainda criança, submetendo-se a um trabalho penoso para contribuir com sua família na obtenção do alimento: 
Tinha dia que eu chegava em casa com a cara inchada das mordidas de marimbondo, mas eu tinha que ficar constantemente nas bananeiras pra pegar as folhas e manter a casa, manter o alimento. Depois veio melhorando um pouco, quando meu pai conheceu um fazendeiro. Ai eu fui colocando o gado no curral e a gente começou a comer um escaldado de leite, e ai foi melhorando um pouco, tendo uma comida mais saudável.

Nesse relato observa-se que, em situações adversas de existência, a busca pela satisfação de uma necessidade imediata - a reposição de elementos essenciais à vida por meio da alimentação - obriga os indivíduos a submeterem-se a circunstâncias nas quais sua integridade física pode ser violada. Essa faceta do labor - a necessidade incessante de manutenção corpórea pela ingestão alimentar - torna o homem submisso às condicionantes definidas por Proença e Poulain (2003) de que o ser humano, norteado pelas suas condições fisiológicas, torna-se dependente do que lhe é imposto pelo meio ambiente e pelas relações sociais.

O tempo referido por Luzimar, sua infância, é aquele cujo retrato foi apresentado no inquérito nutricional realizado no país (A Pesquisa Nacional sobre Demografia e Saúde - PNDS, conduzida pela Bemfam com o apoio do IBGE e realizada em 1996) que revelou que crianças desnutridas, ou com baixa estatura, correspondiam, em 1996, a 10,4\% da população infantil brasileira. E o cenário, o Nordeste rural, no qual Monteiro (2003) constatou que o risco de desnutrição chega a ser quase seis vezes maior do que no Centro e Sul urbanos. Ali, uma em cada três crianças apresenta baixa estatura, enquanto nas duas outras regiões uma em cada vinte encontra-se na mesma situação.

Esse panorama de déficit nutricional foi sendo modificado ao longo de 20 anos. De acordo com Lima e colaboradores (2010), a prevalência da desnutrição no Nordeste brasileiro foi reduzida em um terço de 1986 a 1996 (de 33,9\% para 22,2\%) e em quase três quartos de 1996 a 2006 (de 22,2\% para 5,9\%). Melhorias na escolaridade materna e na disponibilidade de serviços de saneamento foram particularmente importantes para o declínio da desnutrição no primeiro período, enquanto no segundo período foram decisivos o aumento do poder aquisitivo das famílias mais pobres e, novamente, a melhoria da escolaridade materna. A Pesquisa de Orçamentos Familiares (POF 2008-2009) também confirmou uma prevalência de déficit de altura em crianças menores de 5 anos de idade, igual a 5,9\%, durante o período da pesquisa.

Apesar dos avanços relacionados à saúde e nutrição, por outro lado, a região Nordeste do Brasil é a que tem a maior proporção de pessoas ocupadas com idade entre 5 e 17 anos, segundo a Pesquisa Nacional por Amostra de Domicílio (Brasil, 2010). São 12,3\% ou 1,7 milhão de pessoas nessa faixa. Ou seja, um expressivo contingente de crianças e adolescentes estão trabalhando. À ocasião da coleta de dados da PNAD 2009 havia 1.380 .489 crianças de 5 a 14 anos trabalhando no Brasil, o que representa 4,1\% da população nessa faixa etária: de 5 a 9 anos, 122.679 crianças (o,8\% da população de 5 a 9); e de 10 a 14 anos, 1.257 .810 crianças $(7,2 \%$ da população de 10 a 14).

A fala de Marcos, por sua vez, centrou-se na vida adulta, mas a situação de exposição a agravos é similar. No setor de transportes a alimentação é condicionada ao próprio ritmo do trabalho. A necessidade de realizar entregas dentro de um prazo previsto expõe os motoristas a horários irregulares de refeições, fator que influencia diretamente o seu estado de saúde.

Hoje em dia isso acontece muito [...], tem deles (motoristas) que ficam obesos porque chegam a passar oito a nove horas dentro de uma cabine $e$ comem aquelas comidas que não são totalmente nutrientes. [...] Quando chega pra descarregar, em todo posto fiscal tem bar, restaurante; então eles engrenam, sabem que vão ficar ali no mínimo 12 horas parados, então bebem muito e comem [...].

Estudos comprovam que existe alto índice de obesidade entre os trabalhadores do setor de transportes, principalmente os motoristas. Cavagioni e colaboradores (2008), em estudo transversal, demonstram um índice de $82 \%$ de motoristas com doenças metabólicas, incluindo a obesidade, superando os achados de outros estudos transversais de cunho nacional, como o que foi realizado na Região Metropolitana de Belo Horizonte (MG), com prevalência de sobrepeso em 31\% dos avaliados e obesidade em 6\% (Velasquez-Meléndez e col., 2004). 
Nessa mesma linha, o estudo de Pelotas, RS, verificou que $15 \%$ dos indivíduos do sexo masculino se encontravam obesos, segundo Duarte (2005). Sabe-se que o sobrepeso isoladamente não tem efeito imediato no desenvolvimento de doenças crônicas, porém a história de excesso de peso pode contribuir para variantes que coloquem em risco a saúde.

Para Marcos, o quadro de obesidade que apresenta hoje é uma consequência de seu trabalho. $\mathrm{O}$ estresse gerado pela rotina desgastante e os horários irregulares das refeições, segundo sua reflexão, contribuíram bastante para o desencadeamento desta doença.

[...] parte da minha obesidade eu descobri que também tem parte da ansiedade. Tudo que eu vou fazer quero uma certa rapidez e eu estou aprendendo aos poucos [...] eu não comecei a ser motorista já obeso. Foi em função do tempo. O primeiro a chegar e último a sair; trabalhava de madrugada e fora de hora, e aí não tinha noção do que eu estava comendo.

O estudo realizado por Cavagioni e colaboradores (2008) com 258 motoristas rodoviários revelou que $82 \%$ eram obesos e possuíam outras doenças metabólicas associadas, como dislipidemias, hipertensão e diabetes. Uma pesquisa com 124 motoristas realizada pela Associação Brasileira de Estudo da Obesidade e Síndrome Metabólica (Abeso) descobriu que $60 \%$ deles estavam com excesso de peso, o que demonstra a presença expressiva de obesidade entre os trabalhadores desse setor.

Para Arendt, a característica comum ao processo biológico do homem e ao de crescimento e declínio do mundo é que ambos fazem parte de um movimento cíclico da natureza. Sendo cíclico, esse movimento torna-se infinitamente repetitivo de forma que o labor move-se sempre no mesmo círculo prescrito pelo processo biológico do organismo vivo, e o fim só advém com a morte. O labor, trata-se, portanto, de uma atividade extremamente necessária à permanência do homem na Terra. Embora as suas condições de realização sejam por vezes difíceis e exijam sacrifícios, o homem se submete a ela, seja por períodos curtos (como as mordidas de maribondo relatadas pelo primeiro trabalhador) ou por largas temporadas (tais como a condição de obesidade que os motoristas adquirem devido às dificuldades de se alimentar corretamente no trabalho), para manter-se nesse ciclo, ou seja, manter-se vivo. No entanto, esse esforço de permanência, que tem como consequência a aquisição de condições de saúde indesejáveis, pode ser modificado, e os agravos preveníveis pela adoção de políticas públicas adequadas.

Sendo cíclico e vital, o processo de labor exerce influência sobre as condições do indivíduo para a execução do seu trabalho, ao mesmo tempo em que pode ser influenciado por este. Marcos demonstra essa inter-relação ao autoavaliar a diminuição de seu rendimento no trabalho ao longo dos anos, devido às condições que lhe foram impostas pelo próprio ambiente de trabalho:

[...] Se fosse há 15 anos, para eu trocar um pneu de um caminhão levava no máximo 3 o minutos. Hoje eu levo no mínimo três horas; isso se eu num for ter um infarto dentro do carro.

Pelos relatos autobiográficos dos trabalhadores, pode-se observar que o aspecto alimentar concernente a essa dimensão da condição humana é um componente significativo para a proposição de reflexões e ações que busquem adequar as necessidades nela implicadas, nos planos da saúde individual e coletiva, para promover uma vida mais saudável, principalmente no âmbito laboral.

\section{"0 trabalho": riscos ergonômicos e distúrbios psíquicos em evidência}

O trabalho corresponde ao artificialismo da existência humana. Ele produz um mundo de coisas completamente diferentes de qualquer ambiente natural. E é exercido por diversos fluxos. Com o trabalho o homem pratica a troca em todos os sentidos para cumprir sua permanência na terra. A condição humana do trabalho é a mundanidade. Uma das qualidades dessa condição humana é criação, e o registro, em código próprio, da informação e de sua representação. Com a apropriação e elaboração gera-se o conhecimento (Arendt, 1995, p. 151).

Segundo Hannah Arendt, o ciclo da vida biológica, inclusive a humana, é sustentado pelo consumo e pela atividade. 0 que provê os meios de consumo é a atividade, neste caso, o trabalho. A autora propôs uma definição prática do que caracteriza como trabalho; entretanto, para um maior aprofundamento no tema em questão, consideramos necessária uma distinção entre labor e trabalho. 
Ao contrário do labor, que, como já dissemos, move-se sempre nos mesmos ciclos prescritos pelos processos biológicos do organismo vivo, que só cessam com sua morte, o trabalho, também designado como obra ou fabricação, termina quando o objeto está acabado, pronto para ser acrescentado ao mundo comum das coisas.

Assim, enquanto o labor limita-se ao campo das necessidades vitais, o trabalho é algo mais elaborado e, por meio dele, o homem cria seus objetos, transformando a natureza e criando um habitat próprio (Arendt, 1995). A utilidade do trabalho permite ao homem demonstrar sua capacidade criativa e se diferenciar dos outros animas, que somente realizam labor.

No parágrafo 196 da obra "Princípios da filosofia do direito", Hegel (1982) caracteriza o trabalho como uma atividade mediadora, que consiste em produzir e adquirir meios particularizados. Por meio dele, o homem adota procedimentos variados, capazes de diferenciar o material oferecido pela natureza e adaptá-lo a múltiplas finalidades, de modo que utiliza essencialmente para seu consumo produtos do trabalho e esforços humanos investidos nesses produtos.

De acordo com Magalhães (2007), essa atividade de transformação das matérias naturais em produtos de atividade humana não é um movimento "apenas repetitivo", mas essencialmente criador: o ato individual de criação de um objeto torna-se o momento através do qual a natureza interioriza-se no processo de trabalho e no qual o homem se faz objetivo e real, na “[...] transformação prática do mundo" (p. 34).

Trazendo essas definições para o contexto dos trabalhadores do setor de transportes, observa-se que nesse caso a definição de trabalho está ligada ao sentido que a atividade de transportar pessoas e cargas significa para esses trabalhadores. Nesse caso, o trabalho possui uma conotação maior do que a ação de transformar a matéria em si. É também capaz de transformar outras vidas e, ainda, de responsabilizar-se por elas.

Os trabalhadores do setor de transportes não fabricam um objeto propriamente dito; entretanto o seu trabalho é de grande relevância para a população, uma vez que esses trabalhadores atuam interligando vários setores da sociedade. É amplamente conhecido o caráter essencial dos transportes, não só como infraestrutura para os processos de produção, mas também como pré-requisito para uma boa qualidade de vida dos cidadãos.

Segundo Siqueira (1996), o setor de transportes possui elevada responsabilidade social, uma vez que o consumo de vários bens intimamente ligados às condições de vida e aos direitos dos cidadãos depende dos transportes. Habitação, trabalho, saúde, educação e convívio social pressupõem condições de locomoção para a sua satisfação.

Ao exercer sua atividade laboral o trabalhador do setor de transporte lida com algo que se configura como uma máquina e não como uma ferramenta. Segundo Arendt (1995), talvez o melhor exemplo da diferença fundamental entre ferramentas e máquinas seja a discussão, aparentemente infindável, se o homem deve ajustar-se às máquinas ou se essas devem ajustar-se à natureza humana.

Nunca houve dúvida de que o homem se ajustava - ou precisava de ajuste especial - às ferramentas que utilizava. 0 caso das máquinas é inteiramente diferente. Ao contrário das ferramentas de artesanato, que em nenhuma parte do processo de trabalho deixam de ser servas das mãos, as máquinas exigem que os operários as sirvam, que ajustem o ritmo natural do seu corpo ao seu movimento mecânico. 0 relato de Luzimar demonstra as dificuldades encontradas para realizar esse tipo de adequação no setor de transportes.

Temos uma dificuldade muito grande. Ficar muito tempo sentado prende a circulação do sangue [...] Quando se levantam (motoristas e cobradores) sentem o corpo todo desamparado, e tem muitos motoristas que ficam assim porque a cadeira não tem conforto nenhum. Eu me sento pra frente porque a minha coluna não suporta mais, as cadeiras são desreguladas - a empresa alega que não pode fazer uma cadeira especificamente pra cada cobrador. Muitos adoeceram ano passado de hemorroidas [...]. Na verdade hoje em dia os veículos vêm pra gente se adaptar a eles e não pra eles se adaptarem à gente.

Certamente isso não implica que os homens, em tal caso, se ajustem ou se tornem servos de suas máquinas, mas significa que, enquanto dura o trabalho, o processo mecânico substitui o ritmo do corpo humano. Trazendo para o âmbito do transporte, 
pode-se pressupor que enquanto o trabalho com a máquina (ônibus/caminhão) está sendo realizado o operário dessa máquina (cobrador/motorista) entra no ritmo mecânico, ajustando-se às condições de utilização. Em muitos casos, esse acontecimento pode gerar danos à saúde do trabalhador, como foi evidenciado nos relatos.

Além do desgaste próprio do trabalho, tais profissionais precisam lidar com situações adversas que surgem ao longo do caminho. A superlotação e desconforto dos veículos não incomodam apenas os trabalhadores do setor, mas também os passageiros, acarretando reclamações constantes e gerando um ambiente de maior tensão para trabalhadores e usuários. Nesse sentido, Paes-Machado e Levenstein (2002) referem que as dificuldades de relacionamento são agravadas pela insatisfação dos usuários quanto ao serviço ofertado, tanto pela incompatibilidade entre oferta e demanda quanto pelo tempo de espera em locais sem abrigo ou no tempo perdido no congestionamento do trânsito, resultando em conduta agressiva e conflitos no interior do ônibus, entre os próprios passageiros e destes com os rodoviários.

Vale salientar que a própria organização da sociedade brasileira, voltada para os interesses individuais em detrimento dos coletivos e baseada no estímulo ao consumo, tem relação com o modo de produção vigente e reforça comportamentos e atitudes individualistas. Isso deteriora ainda mais as relações nos espaços públicos, dada à perda da cortesia, solidariedade e interesses comuns.

Por outro lado, Neri e colaboradores (2005) ressaltam que as condições ergonômicas dos veículos de transporte de passageiros e de cargas são um aspecto importante para a saúde e segurança dos trabalhadores do setor de transporte. As precárias condições de instalações são prejudiciais, por exemplo, para a coluna vertebral dos motoristas profissionais que passam horas a fio sentados ao volante. $\mathrm{O}$ assento é, na maior parte das vezes, a principal causa das dores nas costas, pois em muitos veículos os itens ergonômicos mínimos necessários para o conforto e maior adequabilidade do trabalhador ao instrumento de trabalho não são atendidos.

De acordo com Mendes e Dias (1991), no âmbito das relações saúde-trabalho os trabalhadores buscam o controle sobre as condições e os ambientes de trabalho, para torná-los mais “saudáveis", sendo este um processo lento, contraditório e desigual no conjunto da classe trabalhadora, o qual depende de sua inserção no processo produtivo e do contexto sociopolítico de determinada sociedade. Nessa perspectiva, abre-se a discussão a respeito da saúde do trabalhador, de modo que a mesma busca a explicação sobre o adoecer e o morrer dos trabalhadores, em particular por meio dos estudos dos processos de trabalho, de forma articulada com os conjuntos de valores, crenças e ideias, representações sociais e possibilidade de consumo de bens e serviços na moderna civilização urbano-industrial (Dias, 1991).

Esses relatos conduzem a uma correlação direta entre o modo como o trabalho é realizado e as condições de saúde do trabalhador que o executa, não estando relacionada apenas ao ritmo imposto pela máquina, mas também àquele determinado pelo desempenho do trabalho em si. A ergonomia apresenta-se como um elemento importante para discussão por condições mais adequadas de trabalho para esses indivíduos.

Mas não foram somente os agravos relacionados ao físico que apareceram nos relatos dos trabalhadores. Os distúrbios psíquicos também foram citados. Luzimar foi acometido por doenças relacionadas ao trabalho, principalmente aquelas vinculadas ao estresse, causadas por uma problemática constante no transporte público: a falta de segurança. De acordo com sua narrativa, chegou a ser afastado da empresa devido a tais problemas:

[...] a segurança é precária em nosso Estado, e quando os marginais chegam eles querem o dinheiro; $e$ só tem dez reais, mas eles não aceitam dez reais. Tinha dia que eu acordava pensando que estava sendo assaltado, vivia nervoso, estressado e a empresa chegou pra mim e disse que isso não era uma doença não, estresse não era doença não.

O levantamento de Costa e colaboradores (2003), realizado com 1.762 motoristas de São Paulo (capital) e Belo Horizonte, demonstra que em Belo Horizonte a tensão e o estresse atingem 38,5\% dos motoristas. Verificou-se, nas respectivas pesquisas de campo, uma alta incidência de violência dentro dos ônibus, maior em Belo Horizonte do que em São Paulo, especialmente assaltos à mão armada e agressões verbais. Em 2000 e 2002, respectivamente, 38,5\% 
dos profissionais paulistas e $43,4 \%$ dos belo-horizontinos indicaram a ocorrência de um assalto à mão armada ao ônibus em que trabalharam nos 12 meses anteriores.

Pesquisas mostram que as atividades ligadas ao setor de transporte rodoviário são de elevado risco à saúde física e mental do trabalhador. Waldvogel (1999) constatou que há uma significativa participação dos trabalhadores do setor de transportes em casos de mortes, doenças, acidentes do trabalho e de trajeto. De modo que 30\% dos acidentes de trabalho relacionados aos transportes atingem principalmente motoristas e cobradores. Tendo em vista a importância desses trabalhadores no direito de ir e vir da sociedade, o autor aponta para urgentes compromissos com a criação de condições de trabalho e saúde para esse profissional.

Outro aspecto relacionado a distúrbios psíquicos citado pelos trabalhadores é a utilização de substâncias estupefacientes por motoristas. A prática é utilizada pelos trabalhadores do setor para se manterem acordados e dentro dos horários de trabalho previstos. Marcos fala das experiências vivenciadas:

Muitos deles usam por incentivo de outro. Existe um pouco da necessidade, mas todo dia é assim. Se você chegar antes você tem uma premiação, mas se eu disser o valor évergonhoso, porque éum valor baixo pra você colocar sua vida em risco. $O$ "arrebite" (anfetaminas) geralmente são aqueles azulzinhos, então tem deles que trocam o dia pela noite. Na noite você gasta menos pneus, mas o arrebite coloca em risco a sua vida, ele dá efeitos colaterais e, geralmente, a maioria dos usuários de "arrebite" usa outro tipo de droga, porque ele não consegue se manter só com aquela [...].

De acordo com os dados do Observatório Brasileiro de Informações Sobre Drogas de 2005, o Nordeste é o segundo maior consumidor de anfetaminas, classe à qual pertencem os "arrebites”. Nessa região, o,2\% de indivíduos são dependentes de estimulantes e o maior grupo consumidor é formado por motoristas rodoviários, os quais trabalham durante muitas horas e não conseguem se manter acordados para suprir as necessidades impostas pelo trabalho. De acordo com essa mesma pesquisa, a maioria dos entrevistados relatou ganho de peso ao interromper o uso dos estimulantes.
Sabe-se que as condições de saúde dos trabalhadores possuem relação direta com o capital, uma vez que na sociedade capitalista a necessidade de altos lucros por parte dos empresários faz com que estes exijam dos motoristas grandes esforços, geralmente maiores do que as suas possibilidades. Esses, por sua vez, submetem-se à utilização de diversos meios para cumprir com as exigências que lhes são impostas.

Discutir a essência do trabalho a partir de Aren$\mathrm{dt}$, comparando suas dimensões e seu significado com as do labor e do trabalho, e chamar atenção para a temática da saúde do trabalhador a partir dessa comparação é de extrema relevância no processo formador desses indivíduos. Com o trabalho o ser humano é capaz de transformar a matéria. Um bom estado de saúde otimiza esse processo, promovendo ações criativas e geração de arte, o que faz avançar o capital cognitivo humano e brotar ideias capazes de incrementar a resolução dos problemas enfrentados. Por outro lado, trabalhar sob condições inadequadas minimiza essas potencialidades. A inventividade transmuta em necessidade, perdendo em qualidade, gerando insatisfação e tornando trabalho um processo penoso, árduo e adoecedor.

\section{"A ação": participação sindical e inclusão digital para pronunciar-se no mundo}

A "ação" é a única atividade da condição humana que só pode ser praticada com outros homens. Corresponde à condição humana da pluralidade. A ação é a condição de toda a vida política do homem na Terra. Nela o homem exerce sua qualidade de inteligência para introduzir seu conhecimento no espaço em que convive, com a intenção de modificar para melhor esse espaço, com a finalidade de estabelecer um acréscimo ao bem-estar de seus habitantes (Arendt, 1995, p. 151).

Arendt (1995) dá à ação um papel relevante na condição humana. Por meio dela o homem é capaz de se distinguir, ao invés de permanecer apenas diferente. Essa distinção é expressa pelo discurso na ação. Ação e discurso permitem que os seres humanos se manifestem uns aos outros enquanto homens. Essa manifestação supera a existência corpórea e está atrelada à iniciativa. Prescindir dela significa abster-se da própria humanidade. 
Agir, no sentido mais geral do termo, significa tomar iniciativa. Pela ação, faz-se o inesperado, o infinitamente improvável. Isso é possível porque o homem é singular, de forma que a cada nascimento surge algo singularmente novo. A ação e o discurso ocorrem entre os homens, em meio a interesses específicos, que variam de grupo para grupo, de modo que a maior parte das palavras e atos, além de revelar o agente que fala e age, refere-se a alguma realidade mundana e objetiva.

Uma importante referência de ação na vida dos trabalhadores entrevistados é a participação de ambos em um mesmo projeto de extensão, no qual há um estímulo direto para que assumam o papel de atores e sujeitos capazes de pensar e de se pensarem, produzindo uma experiência própria no conjunto das representações da sociedade e a adotarem uma postura de indivíduos que refletem as suas ações em busca de melhorias nas condições de trabalho. Por meio desse projeto dissemina-se um incentivo à participação social, estimulando a ação no cotidiano dos trabalhadores participantes, gerando uma "provocação", para que o trabalhador expresse sua vida crítica e criativamente.

O discurso dos trabalhadores mostra um caráter reflexivo, não apenas no âmbito da reflexão, mas, sim, da ação-reflexão, ao se falar sobre questões que interferem na saúde do trabalhador. Um dos participantes do projeto, atuante do sindicato diz:

$\varepsilon$ hoje eu estou lutando pra empresa colocar cortina nos ônibus, porque a empresa não quer colocar cortina e tem um cobrador que está usando camisa comprida no trabalho porque está com os braços todo manchado e a médica disse que é pra ele colocar manga comprida [...] e eu já fui no Ministério do Trabalho, já fiz a denúncia por que está prejudicando a saúde e pode dar câncer de pele [...] (Luzimar).

A participação social dos trabalhadores como parte integrante do sindicato demonstra o desejo de mudança e a ação de existir humanamente, ou seja, “[...] é pronunciar o mundo, é modificá-lo. [...] Não é no silêncio que os homens se fazem, mas na palavra, no trabalho, na ação-reflexão" (Freire, 2004, p. 78). Segundo Arendt (1995), os sindicatos defendem e lutam pelos interesses da classe operária e são responsáveis pela posterior incorporação desta última na sociedade e, sobretudo, pela extraordiná- ria melhora da segurança econômica, do prestígio social e do poder político da classe.

Ao entender a importância do sindicato e perceber uma maior efetividade na atuação deste por parte dos integrantes do projeto, observa-se que os trabalhadores passam a se inserir na sociedade adotando outra postura, passando de um indivíduo totalmente submisso aos comandos de seus patrões e superiores para um indivíduo autônomo que entende os seus direitos e sabe como exercê-los.

Ser dirigente do sindicato é lutar pelos direitos do trabalhador, é defender o trabalhador; e, hoje, o que eu faço no sindicato é defender o direito do trabalhador. (Luzimar)

Além da percepção de uma maior participação social dos trabalhadores, outro ponto abordado nas histórias de vida foi a importância da inclusão digital trazida para os trabalhadores por meio do projeto, que faz com que o indivíduo possa expressar-se, deixar sua marca no mundo, como manifestou Luzimar:

$\varepsilon$ estou muito feliz de estar participando desse projeto foi e está sendo muito importante para mim porque eu aprendi a mexer no computador, lá no sindicato eu já estou mexendo.

0 processo de inclusão digital consiste no acesso à informação que está nos meios digitais, sua assimilação e reelaboração em novo conhecimento, tendo como consequência desejável a melhoria da qualidade de vida das pessoas (Silva e col., 2005). Por meio da inclusão digital, os trabalhadores podem realizar ações com qualidade e de forma mais efetiva, contribuindo para melhoria nas condições trabalhistas, uma vez que o representante social do trabalhador estará atuando com o mesmo nível informacional do seu superior e, assim, obterá mais respaldo na realização de suas indagações. Além de possibilitar uma maior credibilidade ao trabalhador, a inclusão digital também atua de forma a promover um meio de cultura e arte de utilização viável.

$\mathrm{Na}$ fala de outro trabalhador percebe-se a relevância de expor a sua visão do cotidiano por meio das fotografias, e o quanto é importante essa via de expressão, que, por meio da tecnologia informacional, passa a dar voz aos sujeitos silenciados:

O projeto é ótimo, não só para mim, como pra nós todos. Porque a gente pode mostrar o nosso dia a 
dia, não só aqui, mas para todas as pessoas que tem acesso a ver esse projeto na internet com as fotos que nós tiramos. (Marcos)

Arendt nos lembra que a ação é uma atividade irreversível. E, embora os homens sempre tenham sido capazes de destruir tudo que fosse produzido por mãos humanas (através do próprio trabalho), nunca foram e jamais serão capazes de desfazer ou sequer controlar os processos que desencadeiam através da ação. Por esse motivo a ação possui uma conotação tão importante no âmbito de saúde e educação do trabalhador, pois por meio delas torna-se possível uma transformação da realidade, com melhorias à vida do trabalhador.

Outra característica fundamental da ação é que ela não tem fim. Por esse motivo jamais se pode prever com segurança o resultado de qualquer ação. O processo de um único ato pode prolongar-se literalmente até que a própria humanidade tenha chegado ao fim. Assim, ao estimular um trabalhador a agir não se pretende apenas a resolução de um problema atual, mas uma estratégia de disseminação de uma educação reflexiva, de tal forma a envolver diferentes atores no processo, de modo que uma mesma ação possa repercutir em diferentes épocas e lugares da sociedade.

\section{Considerações finais}

Por meio das narrativas pudemos perceber que os três eixos principais da condição humana (labor, trabalho e ação) atuam interligados no cotidiano da vida dos trabalhadores, não sendo possível entendê-los de forma fragmentada. Isso porque o ser humano não se funda em apenas uma perspectiva, mas por um conjunto de fatores que se complementam, como as atividades correspondentes a necessidades vitais, a necessidades mecânicas de se movimentar e de criar objetos e àquelas necessidades de agir na busca de criar um ambiente propício para a condição humana em toda sua dimensão. Nesse sentido, é importante conhecer, compreender e discutir essas três categorias de Arendt para a efetivação de um trabalho reflexivo acerca da saúde do trabalhador, uma vez que todas estiveram presentes nos discursos, mostrando a importância na história de todos e de cada um.
O desenvolvimento da pesquisa com trabalhadores dos transportes trouxe muitas reflexões acerca das condições físicas, ambientais, psicológicas e sociais a que está submetida essa categoria profissional - inclusive aos próprios trabalhadores -, sobretudo num país onde a lógica capitalista reforça o pensamento e o comportamento individualista e o sistema de transporte coletivo por ônibus ainda é dominante, o investimento em novas tecnologias e novos meios de transporte é lento, as redes viárias das grandes cidades não dão conta do volume de automóveis circulantes e urge a necessidade de modernização e de uma efetiva implementação de políticas públicas que melhorem as condições de trabalho e a qualidade de vida de trabalhadores e usuários.

Este trabalho, por ser um relato de experiência de uma ação de extensão em desenvolvimento, tem como limitação o número de trabalhadores do setor de transporte participante, uma vez que entre as categorias incluídas no projeto de extensão só havia dois representantes desse ramo de atividade. Um fator positivo, contudo, foi o ganho em profundidade, uma vez que as histórias narradas revelaram aspectos importantes da vida desses trabalhadores, principalmente porque foram relatos espontâneos. As categorias de Arendt também foram discutidas com eles, aumentando a reflexividade desses profissionais em relação às suas vidas, ao seu trabalho e à possibilidade de ação. Estudos posteriores com essa categoria profissional, como grupos focais, por exemplo, podem ser realizados fomentando a discussão das questões de saúde dos trabalhadores dessa categoria, a partir dos elementos citados pelos entrevistados (insegurança alimentar, doenças crônicas não transmissíveis, riscos ergonômicos, distúrbios psíquicos, participação sindical, inclusão digital). Um estudo qualitativo também pode ser realizado para obtenção de uma visão numérica dos problemas e ideias trazidas pelos dois trabalhadores.

Diante do exposto, percebe-se ainda o quão importante é a criação de espaços/tempos de convivência/reflexão entre trabalhadores e a academia, de tal forma que seja possível criar âmbitos de discussão nos quais se torne viável o desenvolvimento de processos de entendimento de diversos temas de contexto social, bem como a disseminação de práti- 
cas que proporcionem melhorias nas condições de educação, saúde e cultura do trabalhador.

\section{Contribuição dos autores}

Xavier Pinto foi responsável pela orientação e redação final. Moreira e Bezerra foram responsáveis pela pesquisa e redação do artigo. Freire Pequeno foi responsável pela redação.

\section{Referências}

ARENDT, H. A condição humana. 7. ed. Rio de Janeiro: Forense Universitária, 1995.

BARRETO, A. A. A condição da informação. São Paulo em Perspectiva, São Paulo, v. 16, n. 3, p. 6774. 2002.

BRASIL. Ministério do Planejamento Orçamento e Gestão. Instituto Brasileiro de Geografia e Estatística - IBGE. Pesquisa Nacional por Amostra de Domicílios. Síntese de Indicadores 20o9. Rio de Janeiro, 2010.

CAVAGIONI, L. C. et al. Síndrome metabólica em motoristas profissionais de transporte de cargas da rodovia BR 116 no trecho paulista Régis-Bittencourt. Arquivos Brasileiros de Endocrinologia e Metabologia, São Paulo, v. 52, n. 6, p. 1015-1023, 2008.

COSTA, L. B. et al. Morbidade declarada e condições de trabalho: o caso de motoristas em São Paulo e Belo Horizonte. São Paulo em Perspectiva, São Paulo, v. 17, n. 2, p. 54-67, 2003.

DIAS, E. Fotografando os anos 8o. In: BUSCHINELLI, J. et al. Vidas, trabalho e saúde no Brasil. São Paulo: Cortez, 1991. p. 36-48

DOMINICÉ, P. A biografia educativa. In: NÓVOA, A.; FINGER, M. (Org.). O método (auto)biográfico e a formação. Lisboa: Ministério da Saúde, Departamento de Recursos Humanos, 1988. p. 99 $-106$

DUARTE, A. C. et al. Síndrome metabólica: semiologia, bioquímica e prescrição nutricional. Rio de Janeiro: Axcel Books do Brasil, 2005.

FREIRE, P. Pedagogia do oprimido. 39. ed. Rio de Janeiro: Paz e Terra, 2004.
HEGEL, G. W. F. Principes de la philosophie du droit ou droit naturel et science de L'Etat en abrégé. Paris: Vrin, 1982.

LIMA, A. L. L. et al. Causas do declínio acelerado da desnutrição infantil no nordeste do Brasil (1986-1996-2006). Revista de Saúde Pública, São Paulo, v. 44, n. 1, p. 240-251, 2010.

MAGALHÃES, T. C. A atividade humana do trabalho [labor] em Hanna Arendt. Rio de Janeiro: Forense Universitária, 2007.

MENDES, R.; DIAS, E. C. Da medicina do trabalho a saúde do trabalhador. Revista de Saúde Pública, São Paulo, v. 25, n. 5, p. 341-349, 1991.

MONTEIRO, C. A. A dimensão da pobreza, da desnutrição e da fome no Brasil. Estudo de Avaliação, São Paulo, v. 17, n. 48, p. 7-20 2003.

MORIN, E.; NAIR, S. Uma política de civilização. Lisboa: Instituto Piaget, 1997.

NERI, M.; SOARES, W. L.; SOARES, C. Condições de saúde no setor de transporte rodoviário de cargas e de passageiros: um estudo baseado na pesquisa nacional por amostra de domicílios. Cadernos de Saúde Pública, Rio de Janeiro, v. 21, n. 4. p. 1107-1123, 2005.

PAES-MACHADO, E.; LEVENSTEIN, C. Assaltantes a bordo: violência, insegurança e saúde no trabalho em transporte coletivo de Salvador, Bahia, Brasil. Cadernos de Saúde Pública, São Paulo, v. 18, n. 5, p. 1215-1227, 2002.

PROENÇA, R. P. C. P.; POULAIN, J. P.; Reflexões metodológicas para o estudo das práticas alimentares. Revista de Nutrição, Campinas, v. 16, n. 4, p. 365-386, 2003.

SILVA, H. et al. Inclusão digital e educação para a competência informacional: uma questão de ética e cidadania. Revista Info, Brasília, DF, v. 34, n. 1, p. 28-36, 2005 .

SIQUEIRA, M. M. O papel da regulamentação na gestão pública: o exemplo do transporte coletivo por ônibus. Revista de Administração Pública, Rio de Janeiro, v. 31, n. 1, p. 29, 1996. 
ULHÔA, M. A. et al. Distúrbios psíquicos menores e condições de trabalho em motoristas de caminhão. Revista de Saúde Pública, v. 6, n. 44, p. 1130-1136, 2010.

VELASQUEZ-MELÉNDEZ, G.; PIMENTA, A. M.; KAC, G. Epidemiologia do sobrepeso e da obesidade e seus fatores determinantes em Belo Horizonte (MG). Revista Panamericana de Salud Pública, Washington, DC, v. 16, n. 5, p. 308-314, 2004.

WALDVOGEL, B. C. Acidentes de trabalho: os casos fatais: a questão da identificação e da mensuração. 1999. Tese - Faculdade de Saúde Pública da Universidade de São Paulo, São Paulo, 1999.

Recebido: 03/02/2013

Reapresentado: 21/01/2014

Aprovado: 13/02/2014 